\title{
Adherence to drug treatment among schizophrenic patients in Jigawa State, Nigeria
}

\author{
Ado Shehu, ${ }^{1,2}$ Saleh Ngaski Garba, ${ }^{3}$ Emmanuel Ejembi Anyebe, ${ }^{4}$ Mb Tukur, ${ }^{3}$ Hayat Gomma ${ }^{3}$ \\ ${ }^{1}$ Department of Nursing Sciences, Faculty of Basic Health Sciences, Maryam Abacha American University \\ of Niger, Maradi, Niger; ${ }^{2}$ Department of Nursing Services, Federal Medical Centre Birnin Kudu, Nigeria; \\ ${ }^{3}$ Department of Nursing Sciences, Faculty of Allied Health Sciences, Ahmadu Bello University, Zaria, \\ Nigeria; ${ }^{4}$ Department of Nursing Sciences, Faculty of Health Sciences, National Open University of \\ Nigeria, Abuja, Nigeria
}

\begin{abstract}
Schizophrenia is among the most common psychiatric disorders, affecting approximately $1 \%$ of the world's population and is among the leading cause of disability. Adherence to drug therapy is associated with favourable clinical outcomes and good quality of life among schizophrenic patients undergoing treatment. This study assessed the prevalence and factors responsible for adherence/non-adherence to drug treatment among schizophrenic patients in Jigawa State. We used a descriptive hospital-based cross-sectional study design and recruited three hundred and ninety-nine patients using multi-stage sampling technique. The mean and standard deviation of age of the respondents was $42.3 \pm 11.2$. The level of drug adherence was $47.1 \%$. On bivariate analysis, cost of treatment, types of treatment, side effects, and effects of treatment on the performance were found to be associated with low adherence of drugs treatment $(\mathrm{P}<0.05)$. On adjusting for confounding effect using logistic regression analysis, the cost of treatment
\end{abstract}

Correspondence: Ado Shehu, Department of Nursing Services, Federal Medical Centre, Birnin Kudu, Jigawa State, Nigeria.

Tel.: 08069353369

E-mail: comradeadoshehu83@gmail.com

Key words: adherence, drug therapy, schizophrenic patient.

Contributions: AS: conceptualized the design, analysis and interpretation of data as well as drafting the article for intellectual content. EEA: contributed in the analysis, discussion and interpretation of findings. SNG: participated from conceptualization of the research ideas up to analysis and interpretation of research findings. MT and HG contributed in the analysis, discussion and interpretation of data.

Conflict of interest: the authors declare no potential conflict of interest.

Funding: none

Received for publication: 28 May 2019

Revision received: 15 June 2019.

Accepted for publication: 15 June 2019.

This work is licensed under a Creative Commons Attribution NonCommercial 4.0 License (CC BY-NC 4.0).

(C) Copyright: the Author(s), 2019

Licensee PAGEPress, Italy

Annals of African Medical Research 2019; 2:77

doi:10.4081/aamr.2019.77 of more than one thousand naira per day $(\mathrm{AOR}=3.00$, $95 \% \mathrm{CI}=2.75-8.83$ ) and presence of side effects (AOR $=4.01$, $95 \% \mathrm{CI}=1.45-16.09$ ) were found to be predictors of non-adherence to drug treatments. Supervised community treatment, behavioural change communications along with community mental health care financing were recommended in order to increase access and decrease non-adherence to drugs.

\section{Introduction}

Adherence to a drug regime is a significant issue in the clinical management of schizophrenia. ${ }^{1}$ A study of adherence in Bipolar disorder showed that slightly more than one-half of the patients studied were fully adherent, $20 \%$ were partially adherent, and nearly $30 \%$ were non-adherent. ${ }^{2}$ Risk factors for non-adherence in this group included younger age, minority status, substance abuse, and homelessness. ${ }^{2}$ Non-adherence to antipsychotics was slightly higher $(23 \%)$ among those with bipolar disorder but lower for lithium and antidepressants $(26 \%$ and $22 \%)$ respectively. ${ }^{2}$ Lithium was associated with the highest rates of non-adherence in both groups, which reflects the adverse effect burden of the medication. Early treatment discontinuation on the part of patients with schizophrenia or schizophrenia-like disorders is strikingly common, with estimates of its prevalence in antipsychotic drug trials ranging from $25-75 \%$. $^{2}$ It was reported in the USA that adherent patients had a lower rate of psychiatric hospitalization compared with partially adherent and non-adherent patients and were more likely than nonadherent to engage in group therapy, individual therapy, and medication management. ${ }^{3}$ Most patients $(92.0 \%)$ who were adherent in the 6 months prior to hospital admission continued to be adherent 6 months following hospitalization. ${ }^{3}$ However, $75.0 \%$ of previously partially adherent became adherent, and $38.7 \%$ of previously non-adherent became adherent following hospitalization. ${ }^{3}$ The prevalence of either adherence or non-adherence to treatment among schizophrenic patients varies from country to country; and, within the same country it also varies from region to region. Thus, the overall rate of non-adherence was within the range of 30 to $65 \%$ reported in previous studies. ${ }^{2,4,5}$ In Nigeria, a prevalence rate of non-adherence of $54.2 \%, 48 \%$ and $55 \%$ was reported from Maiduguri and Lagos respectively. ${ }^{6-8}$ While a study conducted in South Africa reported a non -adherence rates of $41 \%$ to $43 \%$ among patients with bipolar disorders. ${ }^{2}$ Risk factors for non-adherence included minority status, single status, and substance abuse. ${ }^{2}$ Reasons for non-adherence in this study included forgetting to take medications $(55 \%)$ and adverse effects $(20 \%))^{2}$ Other factors included a disorganized home environment, concern about taking medications for a long term, fear of adverse effects, and lack of information about the illness. One-third of these patients had indi- 
viduals in their core social network (e.g., family, spouse, close friends) who advised against medications. Psychological reasons such as insight, beliefs, and guilt, as well as lack of information about disorders, also play a role in patients' attitudes toward medications resources. $^{2}$

The consequences of early termination of the treatment are significant, making adherence to medication a critical determinant of a generally good prognosis. Discontinuing a prescribed antipsychotic drug is associated with symptom exacerbation, relapse, increased hospitalization, poor long-term course of illness, and higher economic costs of treatment. ${ }^{9}$ Adherence rates for patients with different psychiatric disorders are not very different from one another and are similar to rates among patients with physical disorders. $^{2}$

The problem of non-adherence to medical treatment remains a challenge for the medical professions and social scientists. Although successful adherence interventions do exist, half of interventions seem to fail. ${ }^{10,11}$ As a result of the widespread problem of adherence, substantial numbers of patients do not get the maximum benefit of medical treatment, resulting in poor health outcomes, lower quality of life and increased health care costs. ${ }^{9}$ In spite of many advances made in adherence research, non-adherence rates have remained nearly unchanged in the last decades. ${ }^{10}$ Poor adherence to antipsychotic medication in schizophrenia have been associated with rehospitalisation and relapse in cross sectional studies and studies monitoring hospital admissions among patients being in shortage of supplies of antipsychotic medications. ${ }^{12}$ Data from study revealed that $74 \%$ of the patients discontinued their medication before 18 months, i.e. either to nonadherence or to another antipsychotic medication. ${ }^{5,7}$ The Nonadherence to medication regimens is a major obstacle to the success of therapy. Some of the consequences of non-compliance include increased morbidity, prescribing of additional medications, increased physician visits, hospital admissions and increased cost of health care. As defined by Whitney in $2000,{ }^{13}$ the factors commonly associated with relapse include poor adherence treatment which is thought to be the most crucial issue, substance abuse. ${ }^{14}$ The medication compliance for psychiatric illness is $58 \%$. More specifically, about half of the patients with schizophrenia are nonadherent to treatment. This non-adherence may be due to factors that are patient-related (e.g. substance abuse, forgetfulness, anxiety about side-effects, inadequate knowledge, lack of insight, lack of motivation, fear of stigma); health care-related (e.g. poor patient/health care provider relationship, poor services and access to services, and poor staff training); socio-economically related (e.g. illiteracy, low level of education) or treatment-related (e.g. polypharmacology, complex treatment regimens). ${ }^{14}$ The number of individuals in the population receiving antipsychotic drugs that have been grouped into older and newer classes is surprisingly high and most of whom treated with these antipsychotic medications are unmarried and unemployed, and may live with persistent psychotic and negative symptoms and cognitive impairments. ${ }^{15-17}$ The degree to which an individual follows medical advice is a major concern in every medical specialty. ${ }^{16}$

Patients with acute conditions are more likely to be adherent than those with chronic disorders. ${ }^{2}$ Non adherence rates in patients with schizophrenia, bipolar disorder, and depression are often greater than $50 \%$, which is not very different from patients with no psychiatric chronic diseases. ${ }^{6,8}$ Non-adherence in patients with mental illness can have severe consequences, such as relapses and re-hospitalizations. ${ }^{7}$ As drug therapy experts, pharmacists can help ensure that patients receive safe and effective medication therapy, receive the most benefit from the medication that is prescribed, and achieve optimal medical therapy outcomes. ${ }^{15,17}$ To do this effectively, community psychiatric nurses must be aware of the barriers to adherence in patients who are mentally ill and knowledgeable about intervention strategies that can improve adherence. ${ }^{2}$

Non-adherence also may increase the risk of toxicity among patients who adjust their own medications. ${ }^{6,16}$ Patients with mental illness who are non-adherent also are at risk for homelessness, incarceration, and violence. ${ }^{7,12}$ Poor adherence can be responsible for avoidable hospital admissions and increased visits to the emergency department. ${ }^{2}$ Thus, since adherence is determined to a large extent by one's income, it means non-adherence in a significant proportion of the subjects might be accounted for by these economic considerations. This finding is in tandem with that of a study by Ibrahim et al. who also reported the cost of medication as an important predictor of non-adherence. ${ }^{6}$ Logistic regression analysis also showed that subjects who were on more than one drug (polytherapy) were over two times more likely to be nonadherent to their medications when compared to their counterparts

Table 1. Socio-demographic characteristics of the study participants.

\begin{tabular}{|c|c|c|}
\hline Variables & Frequency & Percentage (\%) \\
\hline $\begin{array}{l}\text { Age range } \\
20-29 \\
30-39 \\
40-49 \\
50-59 \\
60-69 \\
\text { Total } \\
\text { Mean } \pm \text { SD }\end{array}$ & $\begin{array}{c}132 \\
100 \\
62 \\
57 \\
48 \\
399 \\
42.3 \pm 11.2\end{array}$ & $\begin{array}{c}33.1 \\
25.1 \\
15.5 \\
14.3 \\
12.0 \\
100.0\end{array}$ \\
\hline $\begin{array}{l}\text { Educational status } \\
\text { Non formal education } \\
\text { Primary } \\
\text { Secondary } \\
\text { Tertiary } \\
\text { Total }\end{array}$ & $\begin{array}{c}115 \\
58 \\
184 \\
42 \\
399\end{array}$ & $\begin{array}{c}28.8 \\
14.5 \\
46.1 \\
10.5 \\
100.0\end{array}$ \\
\hline $\begin{array}{l}\text { Sex } \\
\text { Male } \\
\text { Female } \\
\text { Total }\end{array}$ & $\begin{array}{l}215 \\
184 \\
399\end{array}$ & $\begin{array}{c}53.9 \\
46.1 \\
100.0\end{array}$ \\
\hline $\begin{array}{l}\text { Ethnic group } \\
\text { Hausa } \\
\text { Fulani } \\
\text { Others } \\
\text { Total }\end{array}$ & $\begin{array}{c}246 \\
105 \\
48 \\
399\end{array}$ & $\begin{array}{c}61.7 \\
26.3 \\
12.0 \\
100.0\end{array}$ \\
\hline $\begin{array}{l}\text { Religion } \\
\text { Islam } \\
\text { Christianity } \\
\text { Total }\end{array}$ & $\begin{array}{c}331 \\
68 \\
399\end{array}$ & $\begin{array}{c}83.0 \\
17.0 \\
100.0\end{array}$ \\
\hline $\begin{array}{l}\text { Occupation } \\
\text { Farmers } \\
\text { Civil servants } \\
\text { Housewives } \\
\text { Student } \\
\text { Business } \\
\text { Total }\end{array}$ & $\begin{array}{c}189 \\
70 \\
55 \\
46 \\
39 \\
399\end{array}$ & $\begin{array}{c}47.4 \\
17.5 \\
13.8 \\
11.5 \\
9.8 \\
100.0\end{array}$ \\
\hline $\begin{array}{l}\text { Marital status } \\
\text { Single } \\
\text { Married } \\
\text { Divorced } \\
\text { Total } \\
\end{array}$ & $\begin{array}{c}153 \\
224 \\
22 \\
399 \\
\end{array}$ & $\begin{array}{c}38.3 \\
56.1 \\
5.5 \\
100.0 \\
\end{array}$ \\
\hline
\end{tabular}


who were on mono-therapy. ${ }^{18,19}$ Reasons for Non-Adherence of prescribed medication and scheduled dosage among individuals with schizophrenia is a major source of frustration for families and other caregivers. It is also the single biggest cause of relapse and rehospitalisation. ${ }^{9} \mathrm{~A}$ third major reason for non-adherence among individuals with schizophrenia is the side effects of the medications. Antipsychotic medications often have serious side effects that also must be addressed in order for patients to be comfortable enough to take the medications. ${ }^{20}$ These side effects include weight gain, loss of sexual desire and performance, and in some cases diabetes, and can be difficult for patients to cope with. ${ }^{20}$ Another factor in non-adherence is the symptoms of schizophrenia. For example, delusions may be present and this delusion may lead the patient to believe the medication is poison. Some patients do not take their medications due to confusion, disorganization or other cognitive deficits associated with schizophrenia. Here, the caregiver will need to play an important role in helping the person with schizophrenia remain on their medicines by providing support and encouragement to take the medications. ${ }^{20} \mathrm{~A}$ few people do not comply with medication protocols out of fear that they will become dependent on or addicted to the drug(s). ${ }^{20}$

Much attention has focused on methods to persuade patients to adhere to recommendations, without sufficient acknowledgement that avoidance of sometimes complex, costly and unpleasant regi-

Table 2. Medical History of the Patients I.

\begin{tabular}{|c|c|c|}
\hline Variables & Frequency & Percentage (\%) \\
\hline \multicolumn{3}{|l|}{ Duration of illness (years) } \\
\hline $1-5$ & 202 & 50.6 \\
\hline $6-10$ & 99 & 24.8 \\
\hline $11-15$ & 45 & 11.3 \\
\hline $16-20$ & 25 & 6.3 \\
\hline $21-25$ & 17 & 4.3 \\
\hline $26-30$ & 11 & 2.8 \\
\hline Total & 399 & 100.0 \\
\hline \multicolumn{3}{|c|}{ Contacts with the Health Care provider } \\
\hline Psychiatrist & 199 & 49.9 \\
\hline Psychiatric nurse & 101 & 25.3 \\
\hline CHEW & 60 & 15.0 \\
\hline Others & 39 & 9.8 \\
\hline Total & 399 & 100.0 \\
\hline \multicolumn{3}{|l|}{ Admitted in Hospital } \\
\hline Yes & 298 & 74.7 \\
\hline No & 101 & 25.3 \\
\hline Total & 399 & 100.0 \\
\hline \multicolumn{3}{|l|}{ Health Facilities attended } \\
\hline Psychiatric hospital & 248 & 62.2 \\
\hline Social services & 21 & 5.3 \\
\hline Day Centre & 15 & 3.8 \\
\hline Other hospitals & 108 & 27.1 \\
\hline Others (unspecified) & 7 & 1.8 \\
\hline Total & 291 & 100.0 \\
\hline \multicolumn{3}{|c|}{ Member of family with similar condition } \\
\hline Yes & 263 & 65.9 \\
\hline No & 136 & 34.1 \\
\hline Total & 399 & 100.0 \\
\hline \multicolumn{3}{|c|}{ Who among your family member has schizophrenia } \\
\hline Grandfather & 44 & 16.7 \\
\hline Grandmother & 84 & 31.9 \\
\hline Father & 51 & 19.4 \\
\hline Mother & 66 & 25.1 \\
\hline Others & 18 & 6.8 \\
\hline Total & 263 & 100.0 \\
\hline
\end{tabular}

mens may be entirely rational. Numerous studies demonstrated that inadequate compliance and non-persistence with prescribed medication regimens result in increased morbidity and mortality from a wide variety of illness, as well as increased health care costs. ${ }^{6-8,16}$ Preventing rehospitalisation of schizophrenia patients, the identified modifiable factors suggest further need for development and implementation of integrated mental health services in the community.

\section{Materials and Methods}

The study was conducted among schizophrenic patients that were receiving treatment in Hospitals in Jigawa State. A hospitalbased cross-sectional descriptive study design was used. A total of four hundred and thirty-six (436) schizophrenic patients receiving treatment were recruited into the study.

This was done through multi-stage sampling technique. Jigawa State is made up of five Emirate Council and these Councils are further broken down into local Governments Authorities.

Table 3. Medical History of the Patients II.

Variables Frequency Percentage (\%)

Type(s) of treatment

\begin{tabular}{lcc} 
Drugs & 350 & 87.7 \\
ECT & 39 & 9.8 \\
Others & 10 & 2.5 \\
Total & 399 & 100.0 \\
\hline Cost of treatment per day & & \\
<N1000 & 190 & 47.6 \\
₹N1000 & 209 & 52.4 \\
Total & 399 & \\
Any treatment side effects? & & \\
Yes & 280 & 70.2 \\
No & 119 & 29.8 \\
Total & 399 & 100.0 \\
What is/are the side effect? & & \\
Weight gain & 126 & 45.0 \\
Sexual dysfunctions & 60 & 21.4 \\
Vomiting & 74 & 26.4 \\
Others & 20 & 7.1 \\
Total & 280 & 100.0
\end{tabular}

Any relapse due to none compliances to treatment?

$\begin{array}{lcc}\text { Yes } & 201 & 50.4 \\ \text { No } & 121 & 30.3 \\ \text { Not known } & 77 & 19.3 \\ \text { Total } & 399 & 100.0\end{array}$

Does that treatment affect your performance?

$\begin{array}{lcc}\text { Yes } & 255 & 63.9 \\ \text { No } & 90 & 22.6 \\ \text { Not known } & 54 & 13.5 \\ \text { Total } & 399 & 100.0\end{array}$

Table 4. Assessment of the level of adherence to treatment among study participants.

\begin{tabular}{lcc}
\hline Level of drugs adherence & Frequency & Percentage (\%) \\
High level & 188 & 47.1 \\
Low level & 211 & 52.9 \\
\hline Total & 399 & 100 \\
\hline
\end{tabular}


Stage I: Selection of the facilities:- simple random sampling was used to select one health facility each from the listed emirate council above. The hospitals are as follows:

I. Gumel General Hospital

II. Hadejia General Hospital

III. Ringim General Hospital

IV. Psychiatric Hospital Kazaure

V. Federal Medical Centre Birnin-kudu and Rasheed Shakoni Specialist Hospital

Stage II: Selection of study participants (Schizophrenic patients) with the aid of simple random sampling from the above hospitals.

Data was collected using the questionnaire and necessary consent was obtained from the stake holders and respondents. Adequate explanation regarding the study was given, confidentiality was also guaranteed. The outcome variable measured was prevalence and some selected determinants of adherence/nonadherence to medication among the study participants. All the data generated from the study was analyzed using Epi info version 3.5.3. Chi-square test was used to determine significant association between categorical variables. A P-value of $\leq 0.05$ was considered significant. Logistic regression analysis was also conducted as part of statistical analysis. Ethical clearance was obtained from the ethical committee of Jigawa State Ministry of Health and Ahmadu Bello University Zaria before commencement of the study. The provisions of the HELSINKI declaration were respected.

\section{Results}

From the result, three hundred and ninety-nine (399) patients with mean age and standard deviation of $42.3 \pm 11.2$ years participated in the study; with the age group of 20-29 years constituting one third of the study participants. Only about $10 \%$ of the study participants have educational status beyond secondary schools. In terms of ethnicity and tribe, Hausa and Muslims constitute majority of the study population with about half of them engage in farming as their main sources of income (Table 1).

The medical history of the study participants revealed that the duration of illness in about half was within 1-5 years (mean $=7.8$ years). Half of them have come in contact with psychiatrist. Three quarters of the study participants were admitted in the hospital previously and two thirds of the study participants have family members with similar conditions. Furthermore, most of the patients were on drugs treatment, while very few were on both drugs and ECT. Almost, half of the patients spend more than one thousand naira as the cost of treatment and about $70 \%$ complained of side effects of which weight gain was the commonest. About half complain of relapse due to non-compliance (Tables 2 and 3).

Meanwhile, about $188(47.1 \%)$ of the study participants have high level of adherence, while 211 (52.1\%) have low level of adherence to drugs (Table 4).

On bivariate analysis, as shown in Table 5, cost of treatment, types of treatment, side effects, and effects of treatment on the performance (work or academic) were found to be associated with low adherence of drugs treatment among the study participants at P-level of $<0.05$.

After adjusting for the confounding effects using logistic regression analysis; type of treatment (ECT/ combination of ECT and drugs) were found to be negative predictors of low adherence to treatment among schizophrenic patients. While, cost of treatment of more than one thousand naira $(\mathrm{AOR}=3.00,95 \% \mathrm{CI}=2.75-$
8.83) and presence of side effects ( $\mathrm{AOR}=4.01,95 \% \mathrm{CI}=1.45$ 16.09) was positive predictor of low adherence to treatment as those with side effects are three and four times more likely to be non-adherent to treatment compared to those without side effects respectively (Table 6).

\section{Discussion}

Analysis of the levels of adherence revealed that $47.1 \%$ of the study participants were adherent and $52.9 \%$ were non-adherent to drug treatment: this means that about one out of every two study participants was either adherent or non-adherent to treatment. Thus, the overall rate of non-adherence was within the range of 30 to $65 \%$ reported in previous studies. ${ }^{2,4.5}$ Though, the prevalence of non-adherence reported in this study, falls within the range of most studies conducted earlier, the rate was below $66.9 \%$ reported in Egypt and above $34.2 \%$ reported from Jos, Nigeria., ${ }^{4,5-8}$ But, it was similar to findings by Ibrahim et al. (2015) who reported prevalence of adherence and non-adherence of $45.8 \%$ and $54.2 \%$ respectively from the north-eastern Nigeria. ${ }^{6}$ This discrepancy could be attributed to the methodological differences in the studies, such as the tools used for the assessment of adherence and the different cut-off values used for the definition of adherence and nonadherence.

The independent medication-related predictors of non-adherence found in this study were; the cost of the medications, type of treatment, side effect profile and occurrence of relapse following previous non-adherence. In terms of the cost of the medications, the higher the cost of the medication per day, the higher the rate of non-adherence. In this case, subjects whose medications cost more than one thousand naira per day were three times more likely to be non-adherent to their prescribed medications than those whose medication cost less than one thousand naira per day. This finding might not be unconnected to the fact that over $90 \%$ of the study participants are of educational status below tertiary level: this may translate to low socio-economic placement and very low or unpredictable earning. Moreover, Jigawa State is among the bottom five states with the highest poverty rates in the country with over $75 \%$ of the inhabitants living below the $\$ 1$ per day benchmark (National Bureau of Statistics, 2013). The poverty levels might have been further complicated by the close proximity with Kano, the capital city of Kano State as most of the inhabitants, more especially among civil servants reside in Kano and usually come to work on daily basis. Therefore, since adherence is determined to a large extent by one's income, it means non-adherence in a significant proportion of the subjects might be accounted for by these economic considerations. This finding is in tandem with that of Ibrahim et al. who reported the cost of medication as an important predictor of non-adherence to drug treatment among schizophrenic patients. ${ }^{6}$

Multivariate (Logistic) regression analysis also showed that study participants who were on ECT alone, combination of ECT and drugs were two times and three times less likely to be nonadherent respectively compared to those who are on drugs treatment only. This might be due to the fact that there were more care as regards to patients on ECT and combination of drugs and ECT because of close monitoring by the family members that take the patients to hospital.

The last among the significant and independent predictor of non-adherence among the study participants was the presence of side effects. Study participants who reported any form of side effect were four times more likely to be non-adherent than those 
without side effects. Of those who were non-adherent, over $60 \%$ reported side effect. This is because the presence of side effects is associated with significant impairment in the quality of life of the subjects as well as it served as a hindrance to them in carrying out some of their activities of daily living. Secondly, based on this study interaction with some of the patients in our study areas, those who experienced incapacitating side effects, view it as punitive and therefore decline psychiatric medications. This negative view of the side effect profile contributes significantly to non-adherence to psychotropic medications among some African patients. A study by Bonaventura et al., on the impact of side effects on medication adherence among psychiatric patients revealed a similar outcome. ${ }^{10}$

\section{Conclusions}

The level of drug adherence was $47.1 \%$ and that of non-adherence was $52.9 \%$ among the study participants. The cost of treatment of more than one thousand naira per day and side effects were found to be predictors of non-adherence to drug treatments. It was recommended that supervised community treatment, behavioural change communications along with community mental health care financing should be adopted in order to increase access and decrease non-adherence to drugs.

Table 5. Bivariate analysis of medication related variables with the level of adherence to treatment among study participants.

\begin{tabular}{|c|c|c|c|c|}
\hline \multirow[t]{2}{*}{ Variables } & \multicolumn{3}{|c|}{ Level of drugs adherence } & \multirow[b]{2}{*}{ P-value } \\
\hline & High & Low & $\mathrm{X}^{2}$ & \\
\hline $\begin{array}{l}\text { Duration of illness (years) } \\
\qquad \begin{array}{l}1-10 \\
11-20 \\
21-30\end{array}\end{array}$ & $\begin{array}{l}140 \\
30 \\
18\end{array}$ & $\begin{array}{l}161 \\
40 \\
10\end{array}$ & 3.87 & $>0.05$ \\
\hline $\begin{array}{l}\text { Cost of treatment } \\
\quad<\mathrm{N} 1000 \\
\quad \geq \mathrm{N} 1000\end{array}$ & $\begin{array}{c}53 \\
135\end{array}$ & $\begin{array}{l}137 \\
74\end{array}$ & 62.10 & $<0.05^{*}$ \\
\hline $\begin{array}{l}\text { Type of treatment } \\
\text { Drugs } \\
\text { ECT } \\
\text { Combination of drugs and ECT }\end{array}$ & $\begin{array}{l}143 \\
30 \\
15\end{array}$ & $\begin{array}{c}197 \\
9 \\
5\end{array}$ & 23.64 & $<0.05^{*}$ \\
\hline $\begin{array}{l}\text { Side effects } \\
\text { Yes } \\
\text { No }\end{array}$ & $\begin{array}{c}145 \\
43\end{array}$ & $\begin{array}{c}135 \\
76\end{array}$ & 8.21 & $<0.05^{*}$ \\
\hline $\begin{array}{l}\text { Relapse due to non-compliance } \\
\text { Yes } \\
\text { No } \\
\text { Unknown }\end{array}$ & $\begin{array}{l}100 \\
51 \\
37\end{array}$ & $\begin{array}{l}101 \\
70 \\
40\end{array}$ & 1.79 & $>0.05$ \\
\hline $\begin{array}{l}\text { Effects of treatment on performance } \\
\text { Yes } \\
\text { No } \\
\text { Unknown }\end{array}$ & $\begin{array}{l}140 \\
30 \\
18\end{array}$ & $\begin{array}{l}115 \\
60 \\
36\end{array}$ & 17.18 & $<0.05^{*}$ \\
\hline $\begin{array}{l}\text { Ever admitted in hospital } \\
\text { Yes } \\
\text { No } \\
\end{array}$ & $\begin{array}{l}141 \\
47 \\
\end{array}$ & $\begin{array}{l}157 \\
54\end{array}$ & 0.02 & $>0.05$ \\
\hline
\end{tabular}

*Statistically significant difference.

Table 6. Multivariate (Logistic Regression) analysis of predictors of non-adherence to drugs treatment among study participants.

\begin{tabular}{|c|c|c|c|}
\hline Predictors & Crude OR (95\% CI) & Adjusted OR ( $95 \% \mathrm{CI})$ & P-value \\
\hline $\begin{array}{l}\text { Cost of treatment } \\
\quad<\mathrm{N} 1000 \\
\quad \geq \mathrm{N} 1000\end{array}$ & $\begin{array}{c}\text { Referent } \\
4.31(2.14-13.11)\end{array}$ & $3.00(2.75-8.83)$ & $<0.05^{*}$ \\
\hline $\begin{array}{l}\text { Type of treatment } \\
\text { Drugs } \\
\text { ECT } \\
\text { Combination of drugs and ECT }\end{array}$ & $\begin{array}{c}\text { Referent } \\
0.62(0.45-3.88) \\
2.29(0.81-6.61)\end{array}$ & $\begin{array}{l}0.51(0.27-0.76) \\
0.33(0.19-0.75)\end{array}$ & $\begin{array}{l}<0.05^{*} \\
<0.05^{*}\end{array}$ \\
\hline $\begin{array}{l}\text { Side effects } \\
\text { No } \\
\text { Yes }\end{array}$ & $\begin{array}{c}\text { Referent } \\
3.25(2.01-22.75)\end{array}$ & $4.01(1.45-16.09)$ & $<0.05^{*}$ \\
\hline $\begin{array}{l}\text { Effects of treatment on performance } \\
\text { No } \\
\text { Yes } \\
\text { Unknown }\end{array}$ & $\begin{array}{c}\text { Referent } \\
1.23(0.49-8.88) \\
2.50(1.11-12.50)\end{array}$ & $\begin{array}{l}2.00(0.56-21.75) \\
3.00(0.75-31.22)\end{array}$ & $\begin{array}{l}>0.05 \\
>0.05\end{array}$ \\
\hline
\end{tabular}

*Statistically significant difference 


\section{References}

1. Afolayan JA, Peter IO. Prevalence of Schizophrenia among Patients Admitted Into a Nigeria Neuro-Psychiatric Hospital. IOSR J Dent Med Sci 2015;14:9-14.

2. Mahaye S, Mayime T, Nkosi, S, et al. Medication adherence of psychiatric patients in an outpatient setting. Afr J Pharm Pharmacol 2012;6:608-12.

3. Ascher-Svanum H, Faries DE, Zhu B, et al. Medication adherence and long-term functional outcomes in the treatment of schizophrenia in usual care. J Clin Psychiatry 2006;67:453-60.

4. Yang J, Kloud YH, Paik JW, et al. Symptom severity and attitudes towards medication: impacts on adherence in outpatients with schizophrenia. Schizophrenia 2012;134:226-31.

5. Kassis IT, Ghuloum S, Mousa H, Bener A. Treatment noncompliance of psychiatric patients; are patients satisfied from their psychiatrist? Br J Med Med Res 2014;4:785-96.

6. Ibrahim AW, Yahya S, Kwajafa SP, et al. Prevalence and predictors of sub-optimal medication adherence among patients with severe mental illnesses in a tertiary psychiatric facility in Maiduguri, North-eastern Nigeria. Pan Afr Med J 2015;21:39

7. Abiodun A, Owoeye O, Adebayo E, Adewale OC. Prevalence and correlates of poor medication adherence amongst psychiatric outpatients in Southwestern Nigeria. Gen Hosp Psychiatry 2009;31:167-74.

8. Oluseun PI, Andrew TO, Olatunji FA, Njideka UO. Medication adherence among Nigerians with schizophrenia: correlation between clinico-demographic factors and quality of life. Mental Illness 2017;9:6889.

9. Lacro JP, Dunn LB, Dolder CR, et al. Prevalence of and risk factors for medication non-adherence in Patients with Schizophrenia: a comprehensive review of recent literature. Jackson C. Psychiatry 2002;63:892-909.

10. Bonaventura M, Gabriel S, Dupclay L, et al. A patient perspective of the impact of medication side effects to adherence: results of a cross-sectional nationwide survey of patients with schizophrenia. BMC Psychiatry 2012;12:20.

11. Hayness IS, Kaiser W, Priebeb S, et al. Profiles of subjective quality of life in schizophrenic in- and outpatients samples. Pyschiatr Res 1997;153-66.

12. Omranifard V, Karahmadi M, Jannesari Z, Maracy, M. Efficacy of modified compliance therapy for schizophrenia patients. J Res Med Sci 2012;17:S258-63.

13. Whitney N, Glazier R. Community Health Factors Affecting Medication Adherence among the Homeless: A Qualitative Study of Patients' Perspectives. Univ Toronto Med J 2000;82:6-9.

14. Kazadi NJB, Moosa MYH, Jeenah FY. Factors associated with relapse in schizophrenia. Psychiatry 2008;14:53-5.

15. Smith KW, Larson MJ. Quality of life assessments by adult substance abusers receiving publicly funded treatment in Massachusetts. Am J Drug Alcohol Abuse 2010;29:323-35.

16. Skantze K, Malam U, Dencker SJ, et al Comparison of quality of life with standard of living in schizophrenic outpatients. $\mathrm{Br}$ J Psychiatry 2012;161:797-801.

17. Schrier AC, Van de Wetering BJM, Mulder PGH, Selten JP. Point Prevalence of Schizophrenia in Immigrant groups in Rotterdam: Data from Outpatient facilities. Enr Psychiatry 2001;16:162-6.

18. Hayhurst KP, Drake RJ, Massie JA, et al. Improved quality of life over one year is associated with improved adherence in patients with schizophrenia. Eur Psychiatry 2014;29:191-6.

19. Rababa S. Partial adherence with Antipsychotics Medications and factors related to Medication Relapse in Jordanian patient. Eur Sci J 2013;9:20-9.

20. Griffith TH. Caregiver Views on Medication Treatment for Persons with Schizophrenia in a Cultural Context Caregiver Views on Medication Treatment for Persons with Schizophrenia. Transcultural Psychiatry 2012;4:23-6. 